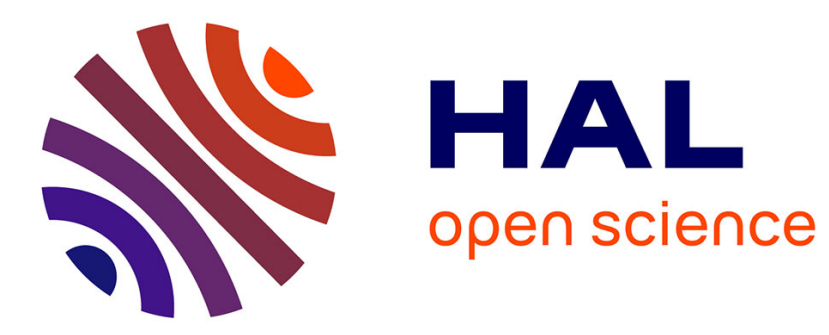

\title{
Evolution of substructure in low-interstitial martensitic stainless steel during tempering
}

F. Niessen, D. Apel, Frederic Danoix, J. Hald, M.A.J. a J Somers

\section{To cite this version:}

F. Niessen, D. Apel, Frederic Danoix, J. Hald, M.A.J. a J Somers. Evolution of substructure in low-interstitial martensitic stainless steel during tempering. Materials Characterization, 2020, 167, pp.110494. 10.1016/j.matchar.2020.110494 . hal-03365756

\section{HAL Id: hal-03365756 \\ https://hal.science/hal-03365756}

Submitted on 5 Oct 2021

HAL is a multi-disciplinary open access archive for the deposit and dissemination of scientific research documents, whether they are published or not. The documents may come from teaching and research institutions in France or abroad, or from public or private research centers.
L'archive ouverte pluridisciplinaire HAL, est destinée au dépôt et à la diffusion de documents scientifiques de niveau recherche, publiés ou non, émanant des établissements d'enseignement et de recherche français ou étrangers, des laboratoires publics ou privés. 


\title{
Evolution of substructure in low-interstitial martensitic stainless steel during tempering
}

\author{
F. Niessen ${ }^{\mathrm{a}, *}$, D. Apel ${ }^{\mathrm{b}}$, F. Danoix ${ }^{\mathrm{c}}$, J. Hald $^{\mathrm{a}}$, M.A.J. Somers ${ }^{\mathrm{a}}$ \\ ${ }^{a}$ Technical University of Denmark, Department of Mechanical Engineering, 2800 Kgs. Lyngby, Denmark \\ ${ }^{\mathrm{b}}$ Helmholtz-Zentrum für Materialien und Energie, Alberst-Einstein-Straße 15, 12489 Berlin, Germany \\ ${ }^{\mathrm{c}}$ Normandie Univ, UNIROUEN, INSA Rouen, CNRS, Groupe de Physique des Materiaux, F-76000 Rouen, France
}

\section{A R T I C L E I N F O}

\section{Keywords:}

Tempered martensite

Lath martensite

$\mathrm{X}$-ray line profile analysis

Orientation mapping

Micro-segregation

Atom probe tomography

\begin{abstract}
A B S T R A C T
The evolution of the substructure and the distribution of interstitial elements in lath martensite during tempering in soft martensitic stainless steel X4CrNiMo16-5-1 was studied with line profile analysis of diffractograms from energy dispersive synchrotron X-ray diffraction, local chemical analysis with atom probe tomography and orientation mapping with electron backscatter and transmission Kikuchi diffraction. Martensite formation occurred below $135{ }^{\circ} \mathrm{C}$ without auto-tempering and led to a dislocation density in martensite of $3.8 \cdot 10^{15} \mathrm{~m}^{-2}$, as determined from X-ray line profile analysis. On tempering, carbon and nitrogen segregated to low-angle and high-angle grain boundaries. Recovery commenced above $550{ }^{\circ} \mathrm{C}$ and led to a reduction in dislocation density to a steady value of $4 \cdot 10^{14} \mathrm{~m}^{-2}$ from 600 to $750{ }^{\circ} \mathrm{C}$. Further tempering led to a second increase in dislocation density at room temperature, owing to the transformation of reverted austenite, formed above $650{ }^{\circ} \mathrm{C}$, into martensite on cooling. It was observed that the recovery of martensite competes with the formation of reverted austenite. The interpretation of the coherently diffracting domain size obtained from X-ray line profile analysis was critically discussed in the context of the internal structure in martensite.
\end{abstract}

\section{Introduction}

Martensitic Fe-Cr-Ni alloys with $>11$ wt.\% $\mathrm{Cr}$ and particularly low $\mathrm{C}$ and $\mathrm{N}$ contents are known as soft martensitic stainless steel. The steel grade is known for good corrosion resistance, good ductility at high strength, excellent impact toughness and particular resistance to wet abrasion and cavitation [1-3]. These properties qualify the material for use in heavy section water turbine components, pump and valve bodies for the power generation and petrochemical industries, and wellhead equipment for the offshore oil and gas industries $[4,5]$.

The material's properties are obtained by solution treating in the austenite region, martensite formation during cooling, and subsequent formation and stabilization of reverted austenite by annealing in the inter-critical temperature region $\left(A_{1}<T<A_{3}\right)$. During slow heating or isothermal annealing the kinetics of reverted austenite formation are diffusion controlled $[6,7]$. Chemical analyses have shown that growth of austenite is accompanied by partitioning of alloying elements [6,8-10]. Such partitioning contributes to the stabilization of reverted austenite at room temperature and below [11,12]. Reverted austenite leads to softening and improves the impact toughness significantly
$[3,4]$.

While the growth stages of reverted austenite at different temperatures are well covered in the literature [10,13-15], the microstructural evolution of martensite before austenite nucleation has received little attention. Generally, before inter-critical annealing, soft martensitic stainless steels are austenitized and quenched to room temperature to form martensite. Transformation to martensite is associated with transformation strains [16] and in lath martensite this is accommodated by the generation of a high dislocation density $\left(\sim 1 \times 10^{15} \mathrm{~m}^{-2}\right)$ [17-19]. On heating the material to a temperature above $\mathrm{A}_{1}$, martensite is tempered while reverted austenite develops [20]. The morphology, chemical composition and strain energy of tempered martensite all affect the nucleation of austenite. It is therefore crucial to characterize these microstructural features of tempered martensite.

The present work elucidates the changes in morphology, local chemical composition and micro-strain, which occur during tempering of soft martensitic stainless steel. To this end, a combination of electron backscatter and transmission Kikuchi diffraction (EBSD and TKD), atom probe tomography (APT) and line profile analysis of energy-dispersive

\footnotetext{
* Corresponding author.

E-mail addresses: contact@fniessen.com (F. Niessen), daniel.apel@helmholtz-berlin.de (D. Apel), frederic.danoix@univ-rouen.fr (F. Danoix), jhald@mek.dtu.dk (J. Hald), somers@mek.dtu.dk (M.A.J. Somers).
} 
Table 1

Chemical composition of X4CrNiMo16-5-1 (EN 1.4418) soft martensitic stainless steel in wt\% and at.\% from optical emission spectroscopy (OES) and C and $\mathrm{N}$ chemical analysis.

\begin{tabular}{lllllllll}
\hline & $\mathrm{Fe}$ & $\mathrm{C}$ & $\mathrm{N}$ & $\mathrm{Cr}$ & $\mathrm{Ni}$ & $\mathrm{Mo}$ & $\mathrm{Mn}$ & $\mathrm{Si}$ \\
\hline wt.\% & Bal. & 0.034 & 0.032 & 15.0 & 5.8 & 1.0 & 0.86 & 0.39 \\
at.\% & Bal. & 0.157 & 0.126 & 15.9 & 5.5 & 0.59 & 0.87 & 0.77 \\
\hline
\end{tabular}

synchrotron X-ray diffractograms is applied.

\section{Experimental procedures}

\subsection{Materials and heat treatments}

The composition of the investigated X4CrNiMo16-5-1 (EN 1.4418) soft martensitic stainless steel is given in Table 1 . The material was received as a $\emptyset 10 \mathrm{~mm}$ rod in as-drawn condition and was heated at a (average) heating rate of $0.75 \mathrm{~K} . \mathrm{s}^{-1}$ to $950{ }^{\circ} \mathrm{C}$, austenitized for $600 \mathrm{~s}$ and quenched to room temperature in an Ar flow at an average cooling

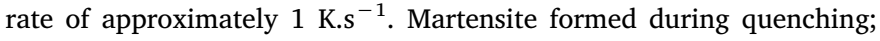
the resulting condition is referred to as the hardened condition.

Specimens for EBSD were ground and subsequently electro-polished for $30 \mathrm{~s}$ at $25 \mathrm{~V}$ with Struers A2 electrolyte to remove the strain-affected surface layer. Electron transparent specimens for TKD were prepared by electrolytic twin-jet polishing in $10 \%$ perchloric acid dissolved in ethanol at $-20{ }^{\circ} \mathrm{C}$.

Specimens for APT analysis were prepared by electrolytic polishing to obtain needle-shaped specimens for field-evaporation, using a standard two-stage method [21]. The investigated specimens were the hardened condition, and tempered conditions achieved by isochronal heating at $0.033 \mathrm{~K} . \mathrm{s}^{-1}$ to final temperatures of 295 and $435{ }^{\circ} \mathrm{C}$.

Specimens for synchrotron X-ray diffraction were cut to $\emptyset 10 \times 0.3 \mathrm{~mm}^{2}$ discs and exposed to isothermal holding for $60 \mathrm{~s}$ at $50 \mathrm{~K}$ intervals from 100 to $800{ }^{\circ} \mathrm{C}$ in a chamber furnace, followed by quenching in water. HajyAkbary et al. [22] found that the dislocation density in lath martensite at $400{ }^{\circ} \mathrm{C}$ was not significantly affected by tempering treatments longer than $5 \mathrm{~s}$. The present holding time of $60 \mathrm{~s}$ was therefore considered sufficient to obtain homogeneous tempering of martensite while minimizing austenite reversion and precipitation of carbides.

\subsection{Orientation mapping with electron backscatter diffraction (EBSD) and transmission Kikuchi diffraction (TKD)}

Orientation mapping was carried out with an FEI Nova NanoLab 600 scanning electron microscope by applying EBSD on bulk specimens and on-axis TKD on electro-polished thin foils. The detector was a Bruker e-Flash EBSD detector. EBSD was carried out at $8.5 \mathrm{~mm}$ working distance with $20 \mathrm{keV}$ beam energy, $4.3 \mathrm{nA}$ beam current and a step-size of $60 \mathrm{~nm}$ between neighboring Kikuchi patterns. In on-axis TKD the electron-transparent specimen is positioned above an OPTIMUS ${ }^{\mathrm{TM}}$ TKD on-axis detector without specimen tilt [23,24]. The beam energy was $30 \mathrm{keV}$, the beam current $1.7 \mathrm{nA}$, the step-size between Kikuchi patterns $12 \mathrm{~nm}$ and the working distance $3 \mathrm{~mm}$.

\subsection{Local chemical analysis with atom probe tomography (APT)}

The instrument used was a CAMECA LEAP $4000 \mathrm{HR}^{\circledast}$. Field evaporation was conducted in voltage mode. The analysis was conducted at $50 \mathrm{~K}, 20 \%$ pulse fraction and $200 \mathrm{kHz}$ pulse rate. The detection rate was $0.3 \%$ in legacy mode. Most of the substitutional elements were observed as doubly charged ions and are thus detected with a mass-overcharge ratio half of their atomic mass. Only Mo also showed triply charged ions, in the region 31-33 Da; Cu was the only element to show singly charged ions, at 63 and $65 \mathrm{Da}$. Regarding interstitial elements, C was detected as $\mathrm{C}^{+}, \mathrm{C}^{2+}, \mathrm{C}^{3+},\left({ }^{2} \mathrm{C}\right)^{2+}$ and $\left({ }^{3} \mathrm{C}\right)^{2+}$, and counted according to Ref. [25]. Identification of $\mathrm{N}$ was more complicated, as this element, singly charged, overlaps with the mass-to-charge ratio of doubly charged $\mathrm{Si}$. In steels containing Mo, $\mathrm{N}$ has a very strong tendency to form molecular ions, MoN, that are detected as $(\mathrm{MoN})^{2+}$. In the current material virtually all $\mathrm{N}$ was detected as $(\mathrm{MoN})^{2+}$, as no characteristic shoulder was observed for the $\mathrm{Si}^{2+}$ peak at $14 \mathrm{Da}$. Therefore only this contribution was considered for N. Average bulk compositions were determined from all data sets with more than 5 million ions and more than 50 million total ions per heat treatment condition. The standard deviation of interstitial content in terms of counting statistics [26] of individual measurements was $<2.5 \times 10^{-3}$ at.\% for both $\mathrm{C}$ and $\mathrm{N}$.

\subsection{Energy-dispersive synchrotron $X$-ray diffraction}

Energy-dispersive synchrotron X-ray diffraction (XRD) was carried out on the EDDI-beamline of the synchrotron facility HZB-BESSY II [27] and comprised measurement of the evolution of the diffraction line profiles of annealed specimens. In the applied energy-dispersive XRD set-up, a beam of white X-rays was applied in reflection geometry at a fixed scattering angle, $2 \theta_{0}=14^{\circ}$. Diffraction for crystallographic planes, $\{h k l\}$, occurs for a photon energy, $E_{h k l}$, which is inversely proportional to the inter-planar spacing, $d_{h k l}$, i.e. proportional to the magnitude of the diffraction vector, $K_{h k l}$ :

$K_{h k l}=\frac{1}{d_{h k l}}=\frac{2 E_{h k l} \sin \left(\theta_{0}\right)}{h c}$

A detailed description of the setup of the EDDI-beamline is given in Ref. [28]. Line profile analysis of energy-dispersive XRD data is uncommon, because of the generally poor instrumental resolution [29-31]. Although the detector resolution has not improved significantly compared to earlier studies, the use of state-of-the-art synchrotron radiation and advances in instrumentation enable significantly better geometrical resolution, implying narrower instrumental line profiles [29]. In the present study, the instrumental resolution was optimized by reducing the cross-section of the primary beam with a $0.5 \times 0.5 \mathrm{~mm}^{2}$ primary slit configuration and limiting the divergence of the diffracted beam by an equatorial slit aperture of $30 \mu \mathrm{m}$. The suitability of this specific experimental setup for line profile analysis of powder specimens has been demonstrated in Ref. [21]. Diffraction patterns for line profile analysis were acquired for $600 \mathrm{~s}$ with an average detector dead time of $34 \pm 3 \%$. The energy dependent instrumental line broadening was characterized by measurement of a standard powder $\mathrm{LaB}_{6}$ SRM660b (NIST), which is shown in Fig. A.1.

\section{Results and interpretation}

\subsection{Microstructure morphology}

Orientation mapping with EBSD and TKD was applied to reveal the microstructure of lath martensite in the hardened condition. The orientation relationship of lath martensite with austenite was identified as Kurdjumow-Sachs (K-S) in a previous investigation [32]. Fig. 1a shows an orientation map obtained with EBSD of a bulk specimen of martensite in the hardened condition. The coloration of the map represents the crystal orientation with reference to the extrusion direction of the material according to the orientation color key in Fig. 1c. As is typical for lath martensite, the microstructure is strictly hierarchical, which is a result of the minimization of the total shape strain [33]. Prior austenite grains (white solid lines) are subdivided into packets (examples given by white broken lines) and blocks (parallel units within packets). Orientation mapping with TKD on an electron-transparent specimen at higher spatial resolution in Fig. 1b reveals that blocks are further subdivided into laths. Fig. 1c shows a magnified area from the map in 
a)

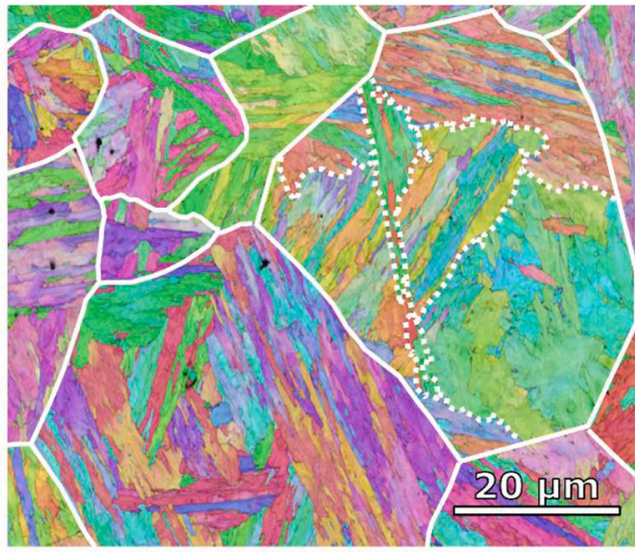

b)

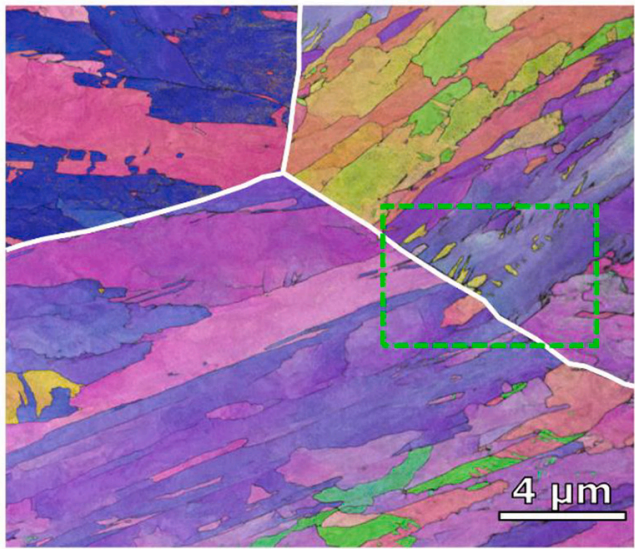

c)

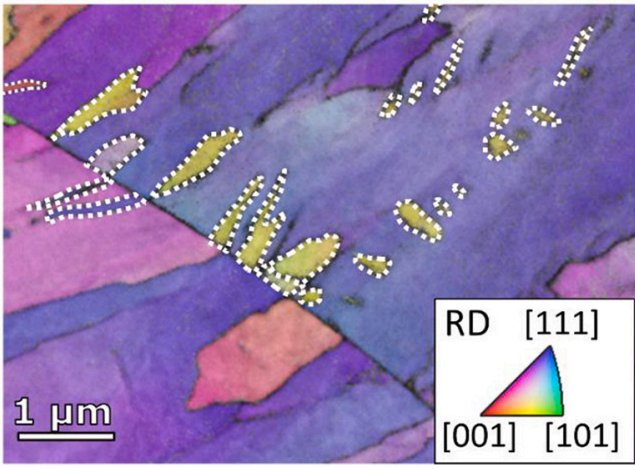

Fig. 1. Orientation maps of the hardened condition (a) Overview map from EBSD showing the hierarchical subdivision of prior austenite grains (solid lines) into packets (examples given by broken lines) and blocks (parallel units within packets); (b) High-resolution map from TKD showing the division of blocks into laths; (c) Magnified section from TKD-map in panel b showing individual laths (marked by dashed lines) that were approximately intersected perpendicular to their longitudinal direction. The average lath thickness, $133 \pm 63 \mathrm{~nm}$, was determined along the thinnest direction of the marked laths.

Fig. 1b. Here laths that are intersected approx. perpendicular by the specimen surface are marked with dashed lines. Measurement along their thinnest direction yields an average lath thickness of $133 \pm 63 \mathrm{~nm}$. Thicker laths in Fig. 1b may not be intersected perpendicular to their thinnest dimension and would thus give a false estimate of the lath thickness.

\subsection{Atom probe tomography}

For all analyzed specimens, evaluation of the desorption pattern for multiple hits revealed the presence of the [011] crystallographic pole, at which the impact density was greatly enhanced (see example in

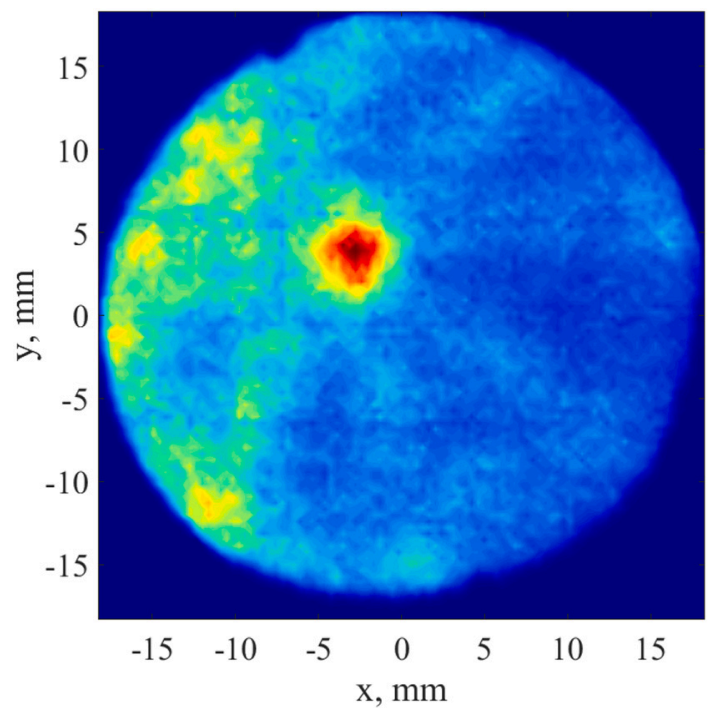

Fig. 2. Desorption pattern of multiple hits showing the presence of the [011] crystallographic pole. The high field-evaporation rate led to an artificial enrichment of $\mathrm{Cr}$ around this crystallographic pole (red area) and was used to identify grain boundaries and to distinguish LAGBs (lath boundaries) from HAGBs. (For interpretation of the references to color in this figure legend, the reader is referred to the web version of this article.)

Fig. 2). Analysis of the distribution of alloying elements revealed that $\mathrm{Cr}$ was systematically enriched along this pole. This Cr-enrichment is an artefact and originates from loss of Fe ions upon multiple hits. This effect is known as the pile-up effect [34-36]. The artefact was exploited to highlight the crystallographic pole with $\mathrm{Cr}$ isoconcentration surfaces of $x_{C r}>23$ at.\% where the average $\mathrm{Cr}$ content is 16 at.\% (Fig. 3). The interruptions and relative shifts of these poles are an indication of the misorientation of adjacent grains and allow to distinguish between lath boundaries, which are low angle grain boundaries (LAGBs) and packets, blocks or prior austenite boundaries, which are high angle boundaries (HAGBs).

In the hardened condition, all elements were more or less homogeneously distributed within the laths and across lath boundaries. Fig. 3a reveals an essentially homogeneous distribution of $C$ across two martensite laths, indicated by the interrupted crystallographic pole (in green). The average bulk concentrations of $\mathrm{C}$ and $\mathrm{N}$ in the hardened condition were $0.164 \pm 0.014$ and $0.126 \pm 0.006$ at.\% (Table 2), respectively, which is in good agreement with the overall composition in Table 1.

Fig. 3b shows the specimen which was tempered by heating to $295{ }^{\circ} \mathrm{C}$. Considerable C enrichment and a large shift of the crystallographic pole indicates the location of a HAGB, while the other segregated features are LAGB's, i.e. lath boundaries. The $\mathrm{C}$ and $\mathrm{N}$ concentrations fluctuate slightly within the laths, which is consistent with the anticipated clustering. Segregation of $\mathrm{C}$ and $\mathrm{N}$ has led to a reduction of the bulk $\mathrm{C}$ and $\mathrm{N}$ concentrations to $0.062 \pm 0.018$ and $0.096 \pm 0.010$ at. $\%$, respectively (Table 2 ).

Peak concentrations at grain boundaries were determined by background corrected 1D concentration profiles with a fixed bin width of $0.5 \mathrm{~nm}$ along the length of a perpendicularly intersecting cylinder. The maximum $\mathrm{C}$ and $\mathrm{N}$ concentrations at observed LAGBs ranged from negligible segregation up to 1.3 and 0.3 at.\%, respectively. The composition profiles of all segregating elements across the HAGB are shown in Fig. 4. The maximum C concentration at the HAGB was 2.6 at.\% which is approx. 40 times higher than in the bulk; the $\mathrm{N}$ concentration only increased by a factor of 4 to 0.4 at.\%. The HAGB was further enriched in $\mathrm{P}$ by a factor 25 , in $\mathrm{Cr}$ by $\sim 1$ at. $\%$, in Mo by $\sim 2$ at.\%, and by minor amounts of $\mathrm{Nb}$ and $\mathrm{V}$ (not shown) in balance with Fe. The low martensite start temperature of $135^{\circ} \mathrm{C}$ in this alloy and the increased $\mathrm{Cr}$ 


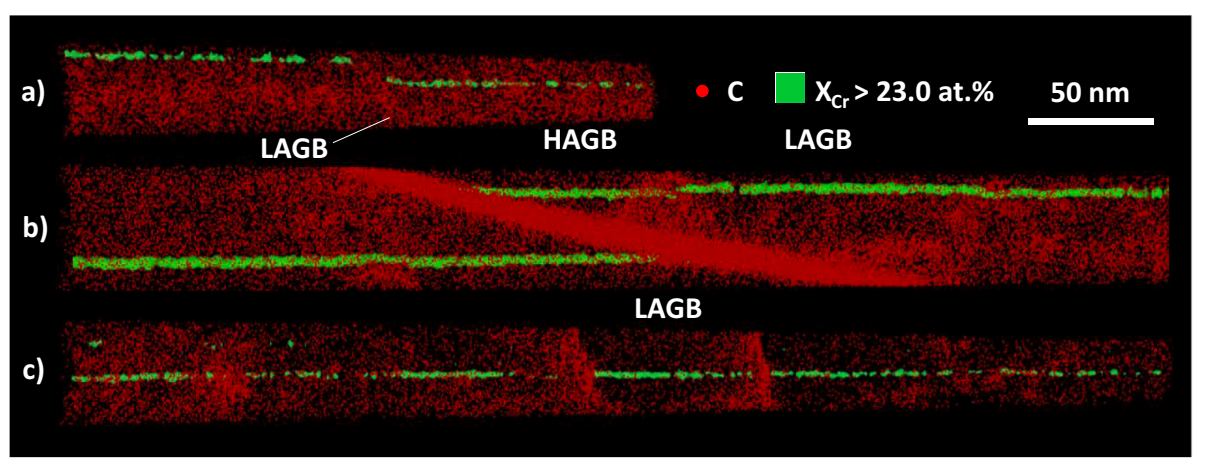

Fig. 3. Atom probe reconstruction of martensite a) in the hardened condition, b) after tempering to $295^{\circ} \mathrm{C}$ and c) after tempering to $435^{\circ} \mathrm{C}$. The red dots represent $\mathrm{C}$ atoms; the green surfaces are $\mathrm{Cr}$ isoconcentration surfaces for $x_{C r}>23$ at.\% (artefact from pile-up effect), indicating crystallographic poles that reveal the presence of and approx. misorientation across grain boundaries. (For interpretation of the references to color in this figure legend, the reader is referred to the web version of this article.)

Table 2

Average $\mathrm{C}$ and $\mathrm{N}$ bulk concentrations of the hardened and tempered conditions in at.\%. The bulk concentrations are average values containing the standard deviation of several measured specimens and were obtained at regions that were uninfluenced by segregation and adjacent depleted zones. Data originates from $>\mathbf{5} \cdot 10^{6}$ ions per specimen and in total $>\mathbf{5} \cdot \mathbf{1 0}^{7}$ ions per tempering condition.

\begin{tabular}{lll}
\hline Condition & $x_{C}{ }^{\text {bulk }}$ [at.\%] & $x_{N}^{\text {bulk }}$ [at.\%] \\
\hline Hardened & $0.164 \pm 0.014$ & $0.126 \pm 0.006$ \\
Tempered $295^{\circ} \mathrm{C}$ & $0.062 \pm 0.018$ & $0.096 \pm 0.010$ \\
Tempered $435{ }^{\circ} \mathrm{C}$ & $0.048 \pm 0.005$ & $0.076 \pm 0.010$ \\
\hline
\end{tabular}

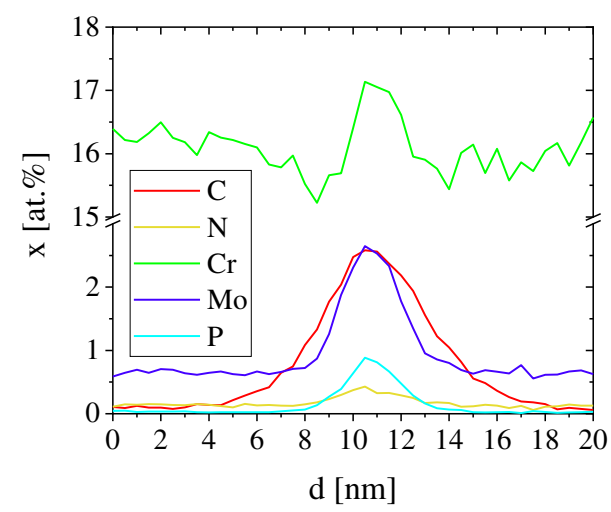

Fig. 4. Background corrected compositional profile across the HAGB shown in Fig. $3 \mathrm{~b}$. The profile shows the integrated atom counts along the length of a perpendicularly intersecting cylinder.

and Mo concentrations at the interface exclude the possibility that the compositional profile is associated with a film of retained austenite. The width of the segregation profile is notably larger than the one of an actual interface. The degradation of the actual interfacial width is instrument-related and known as the local magnification effect [37]. The effect increases with the inclination of the interface, which is high $\left(>60^{\circ}\right)$ in the present case.

The specimen tempered by heating to $435{ }^{\circ} \mathrm{C}$ also revealed segregation of $\mathrm{C}$ and $\mathrm{N}$ to lath boundaries (Fig. 3c). No indications of transition carbides were found, while more clustering of $\mathrm{C}$ was encountered as compared to the specimen that was heated to $295{ }^{\circ} \mathrm{C}$. Continued segregation of $\mathrm{C}$ and $\mathrm{N}$ to lattice defects led to a further reduction of the bulk to $0.048 \pm 0.005$ at.\% for $\mathrm{C}$ and $0.076 \pm 0.010$ at. $\%$ for $\mathrm{N}$ (Table 2). The maximum concentrations of interstitials at observed LAGBs ranged from negligible segregation up to 0.5 and 0.4 at. $\%$ for C and $\mathrm{N}$, respectively. As the overall analyzed volume and thus the number of observed boundaries in APT is relatively low (three to five LAGBs were observed per heat-treatment condition), the reported peak concentrations at boundaries cannot be regarded statistically significant and should be considered mere examples.

\subsection{Energy dispersive synchrotron $X$-ray diffraction}

The instrumental broadening of the diffraction setup was analyzed in a Williamson-Hall plot for $\mathrm{L} \mathrm{LaB}_{6}$ reference powder (see Fig. A.1) and was dominated by Gaussian broadening, reflecting the resolution of the solid state germanium detector; the results are consistent with those generally observed for energy-dispersive XRD [29,30].

The diffraction profile of the hardened condition is given in Fig. 5, and reveals characteristic peaks of martensite and austenite. No asymmetry or splitting of the $200_{\alpha^{\prime}}$ reflection was observed, which is consistent with the presence of cubic martensite with a particularly low interstitial content $[20,38]$. The diffraction data was analyzed with Rietveld refinement, applying the model described in Ref. [29]. Thus, the fraction of retained austenite was determined as $8 \pm 2 \mathrm{vol} \%$. In the diffractograms, the line profiles were fitted with the generalized Thompson, Cox \& Hastings [39] pseudo-Voigt function, yielding the parameters of the Gaussian and Lorentzian contributions to the asmeasured profile to a very good approximation [29].

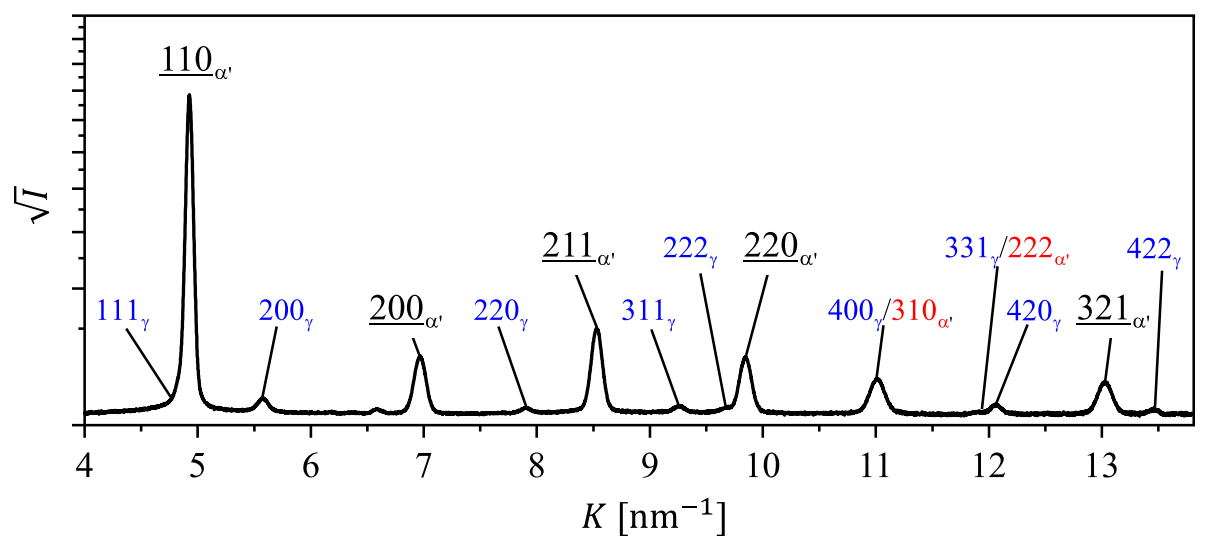

Fig. 5. Diffractogram of the hardened condition. The vertical axis shows the square-root of the integrated intensity, $I$, to reveal reflections of minor intensity; the horizontal axis gives the magnitude of the diffraction vector, $K$. Reflections of austenite are indicated by the blue labels and reflections of martensite that were excluded from line profile analysis are indicated by red labels. Martensite peaks considered for line profile analysis are indicated by the black, underlined labels; The peak at $\mathrm{K}=6.6 \mathrm{~nm}-1$ is an escape peak of the Ge detector originating from the $\mathbf{2 1 1} \boldsymbol{\alpha}_{\boldsymbol{\alpha}^{\prime}}$ reflection. (For interpretation of the references to color in this figure legend, the reader is referred to the web version of this article.) 


\subsubsection{Line profile analysis}

For quantitative line profile analysis, the $110_{\alpha^{\prime}}, 200_{\alpha^{\prime}}, 211_{\alpha^{\prime}}, 220_{\alpha^{\prime}}$ and $321_{\alpha^{\prime}}$ line profiles of martensite were considered. The $310_{\alpha^{\prime}}$ and the $222_{\alpha^{\prime}}$ reflections overlapped with the $400_{\gamma}$ and $331_{\gamma}$ reflections, respectively, and were therefore excluded from the analysis. Further, since none of the austenite reflections had sufficient diffracted intensity for accurate peak fitting, they were not included in the analysis. The Lorentzian and Gaussian contributions to the pseudo-Voigt functions fitted through the as-measured line profiles were corrected for instrumental broadening (see Ref. [40]) and thereafter convolved to the total structurally broadened line profiles with the procedure given in Ref. [41].

The dislocation density, $\rho$, and the size of the coherently diffracting domains, $D$, were determined from the structurally broadened line profiles with the modified Williamson-Hall (MWH) method. This method accounts for strain anisotropy, which induces a non-linear behavior of the magnitude of the diffraction vector, $K$, and the broadening of the line profiles, $\Delta K[31,42]$. The $\mathrm{MWH}$ method applies average dislocation contrast factors, $\bar{C}$, to account for this non-linear behavior $[43,44]$. The structural line broadening, $\Delta K$, is given by [44]:

$\Delta K \cong \frac{0.9}{D}+b M \sqrt{\frac{\pi}{2} \rho}\left(K \bar{C}^{1 / 2}\right)$

where $M$ is the dislocation distribution parameter, a dimensionless constant, $b$ the magnitude of the Burgers vector (here $0.2 \mathrm{~nm}$ ) and 0.9 the Scherrer constant for a spherical crystal with cubic symmetry. An estimate of the maximum detectable domain size, detailed in Appendix 2, was derived from data on the instrumental resolution from Ref. [45] and Eq. (2) and assessed at $110 \mathrm{~nm}$. The detailed procedure for the calculation of the average dislocation contrast factor, $\bar{C}$, can be found in Appendix 3. As the MWH method contains two unknowns, $M$ and $\rho$, the method is semi-quantitative. Following HajyAkbary et al. [22] a suitable value for lath martensite, adopted here, is $M=1.4$.

The modified Williamson Hall analysis was applied to determine the dislocation density and the coherently diffracting particle size for different tempering conditions. An example of a modified Williamson Hall plot is given in Fig. 6. The relationship of $\Delta K$ vs.

$K \bar{C}^{1 / 2}$ evidently follows a linear behavior. The regression line of the $650{ }^{\circ} \mathrm{C}$ condition shows a significantly lower goodness-of-fit value $R^{2}$ compared to the other conditions. Closer inspection shows that the $110_{\alpha^{\prime}}, 220_{\alpha^{\prime}}$ and $200_{\alpha^{\prime}}$ reflections follow a distinct linear relationship with $K \bar{C}^{1 / 2}$, excluding the $211_{\alpha^{\prime}}$ and $321_{\alpha^{\prime}}$ reflections (blue dashed lines in Fig. 6). The origin of this phenomenon is discussed in section 4.4.

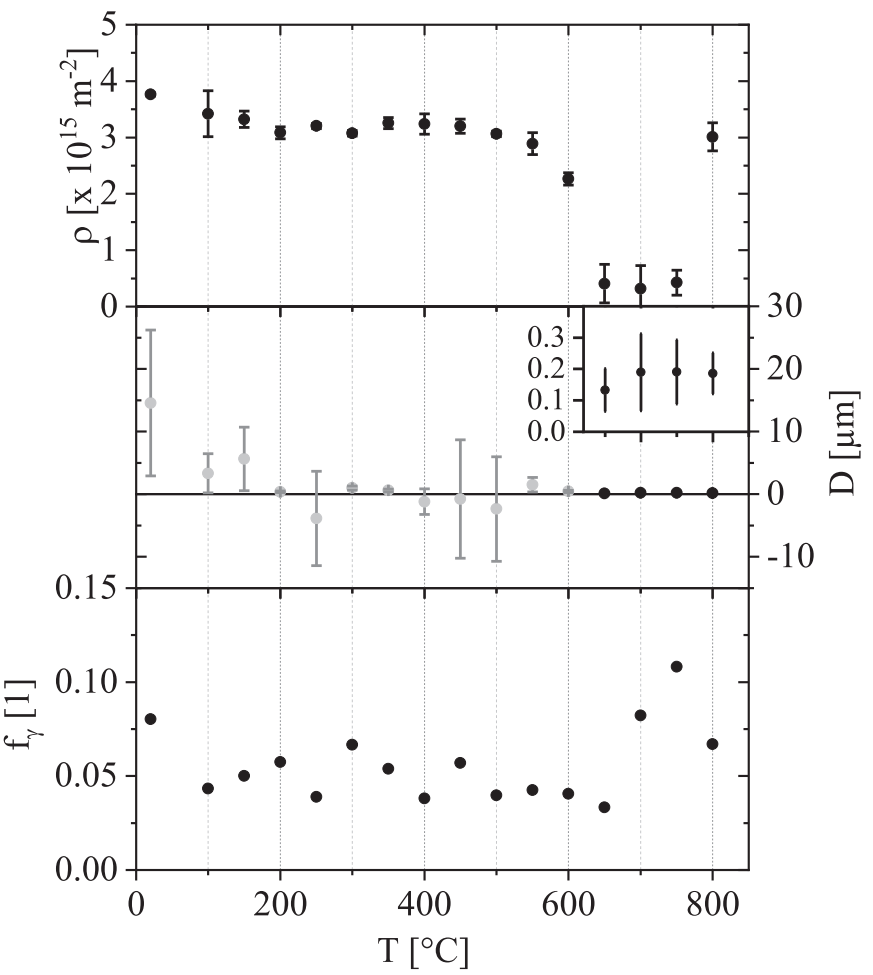

Fig. 7. Dislocation density, $\rho$, average size of coherently diffracting domains, $\boldsymbol{D}$, and fraction of austenite, $\boldsymbol{f}_{\gamma}$, measured at room-temperature after quenching from the indicated tempering temperature. The error bars for $\rho$ and $\boldsymbol{D}$ show the propagated standard error from determining the slope and y-intercept with linear regression, respectively. The error of the phase fraction is in the range of \pm 0.02 [46]. Up to a tempering temperature of $600{ }^{\circ} \mathrm{C}$, the domain size D shows unreasonably large and/or negative values, marked in gray, since the broadening from domain sizes approaches 0 (see Fig. 6); these values are regarded insignificant.

Evaluation of the intercept and slope of the linear regression lines in Fig. 6 in Eq. (1) yields $D$ and $\rho$, respectively. The evolution of dislocation density, coherently diffracting domain size and austenite fraction of the hardened condition and the tempered specimens in the interval 100 to $800{ }^{\circ} \mathrm{C}$ is shown in Fig. 7. The dislocation density of hardened martensite and tempered specimens up to $550{ }^{\circ} \mathrm{C}$ is approximately

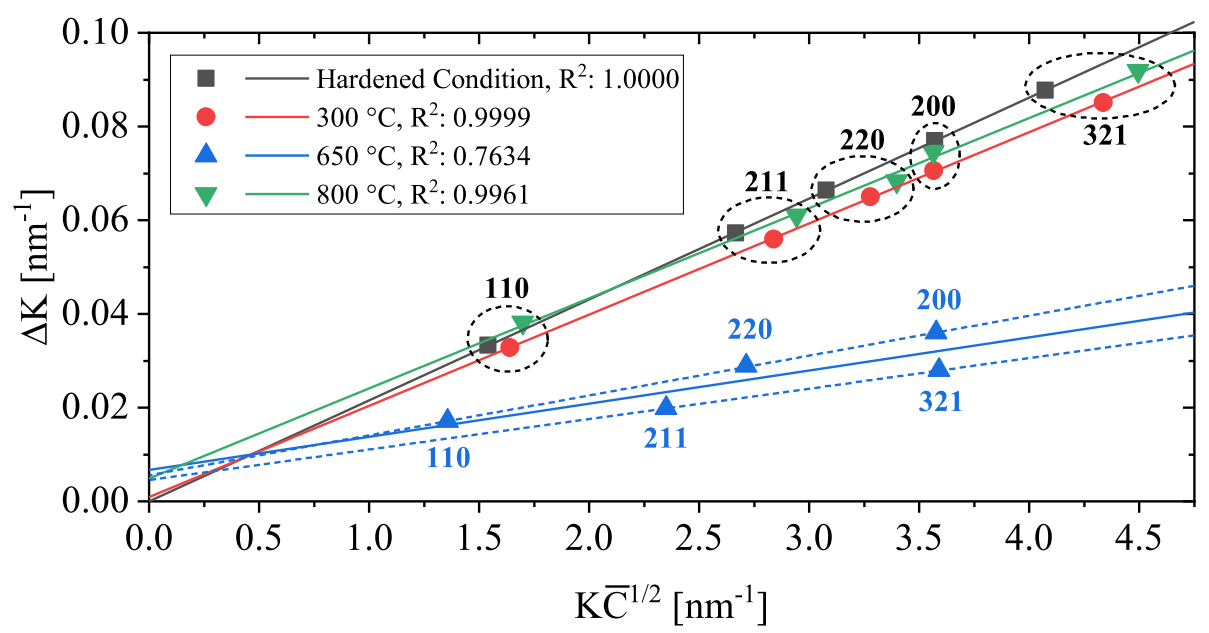

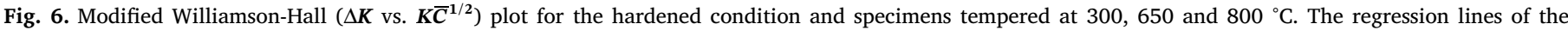

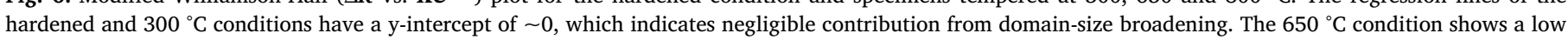

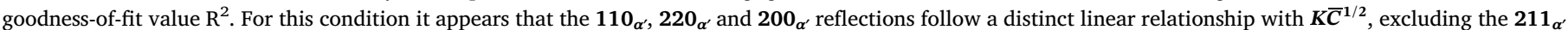

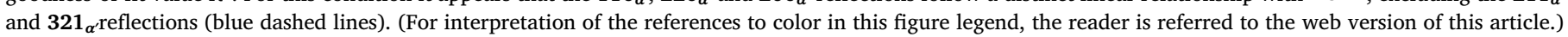


constant within the range $2.9 \cdot 10^{15}-3.8 \cdot 10^{15} \mathrm{~m}^{-2}$. Tempering in the temperature range $650-750{ }^{\circ} \mathrm{C}$ reduces the dislocation density to a steady value of $4 \cdot 10^{14} \mathrm{~m}^{-2}$. Tempering at $800{ }^{\circ} \mathrm{C}$ and cooling to room temperature leads to an increase in dislocation density to $3.0 \cdot 10^{15}$ $\mathrm{m}^{-2}$.

The coherently diffracting domain size of martensite shows unrealistically high positive and negative values of several $\mu \mathrm{m}$ for all tempering conditions up to $600{ }^{\circ} \mathrm{C}$. This is caused by a domain size broadening effect that approaches 0 , rendering the associated domain size values insignificant (see discussion in Section 4.3). Tempering in the temperature range of $650{ }^{\circ} \mathrm{C}$ to $800{ }^{\circ} \mathrm{C}$ is associated with reasonable domain size values in the range of 130 to $190 \mathrm{~nm}$ (see inset in Fig. 7).

The fraction of austenite is initially $8 \mathrm{vol} \%$ and gradually decreases to 3 vol $\%$ after tempering to $650{ }^{\circ} \mathrm{C}$. Tempering at 700 and $750{ }^{\circ} \mathrm{C}$, i.e. above $A_{1}$, and cooling leads to an increase in austenite fraction at room temperature, while tempering to $800{ }^{\circ} \mathrm{C}$ and cooling leads to a second reduction of the austenite fraction at room temperature.

\section{Discussion}

\subsection{Redistribution of alloying elements}

The distribution of alloying elements as measured by APT for the hardened condition does not indicate segregation of interstitial elements. This implies that martensite formation below $\mathrm{M}_{\mathrm{s}}=135{ }^{\circ} \mathrm{C}$ [16] occurred without auto-tempering and that no measurable aging occurred at room temperature during storage for over 6 months. Aging at room temperature is commonly observed for martensitic steels with higher $\mathrm{C}$ content (see for instance the study on a Fe-25Ni-0.4C in Ref. [47]).

After tempering by heating to 295 and $435{ }^{\circ} \mathrm{C}$ an obvious redistribution of the interstitial elements had occurred. Heating to $295^{\circ} \mathrm{C}$ led to segregation of $\mathrm{C}$ and $\mathrm{N}$ to LAGBs and HAGBs. The simultaneous enrichment in ferrite stabilizing elements at the location of the HAGB in Fig. $3 \mathrm{~b}$ indicates that this boundary is a prior austenite grain boundary. Significant grain boundary segregation of substitutional elements is only possible at high temperature where austenite is the only matrix phase. The observed segregation profile in Fig. 4 is typical for grain boundaries in austenitic stainless steels $[48,49]$. The hardened condition should consequently reveal similar segregation of substitutional elements at prior austenite grain boundaries, while segregation of $\mathrm{C}$ and $\mathrm{N}$ could differ. No prior austenite grain boundary was investigated in the hardened martensite condition.

Fig. $3 \mathrm{~b}$ and $\mathrm{c}$ demonstrates that the interstitially dissolved elements, $\mathrm{C}$ and $\mathrm{N}$, progressively segregated to crystal defects with increasing tempering temperature. This finding was supported by in-situ synchrotron XRD measurements in previous work [20].

Comparison of the $\mathrm{C}$ distribution around LAGBs at $435{ }^{\circ} \mathrm{C}$ (Fig. 3c) compared to the hardened (Fig. 3a) and $295{ }^{\circ} \mathrm{C}$ (Fig. 3b) conditions reveals that instead of a sudden clustering of $\mathrm{C}$ at the grain boundary, the $\mathrm{C}$ concentration gradually increases on one side of the LAGBs. This one-sided gradual increase in $\mathrm{C}$ may be associated with the presence of misfit dislocations on one side of the martensite laths. Sandvik and Wayman [50] observed that the mechanical constraint of retained austenite during thickening of martensite laths generates dislocations to accommodate the misfit of the progressing martensite-austenite interface.

\subsection{Dislocation density}

Only few quantitative studies on the dislocation density in soft martensitic stainless steel have been reported in literature. In the present study, the dislocation density of the hardened condition was $\sim 3.8 \cdot 10^{15} \mathrm{~m}^{-2}$ and, upon tempering in the range 650 to $750{ }^{\circ} \mathrm{C}$, decreased to a steady minimum value of $3.1 \cdot 10^{14}$ to $4.3 \cdot 10^{14} \mathrm{~m}^{-2}$. The reduction in dislocation density is caused by recovery of the dislocations between the lath boundaries and occurs in the temperature range of 500 to $600{ }^{\circ} \mathrm{C}$ in $\mathrm{Fe}-\mathrm{C}$ alloys [51]. The newly increase in dislocation density after tempering at $800{ }^{\circ} \mathrm{C}$ is associated with reduced stability of the reverted austenite formed at this temperature, which leads to new martensite formation during quenching.

Christien et al. [19] investigated the evolution of the dislocation density during martensite formation in a commercial 17-4 PH steel with neutron diffraction. The dislocation density was determined by multiplying the squared micro-strain $\Delta K / K$ with a temperature dependent pre-factor, neglecting the contribution from domain size broadening. The pre-factor relates the elastic energy density stored in the bulk with the elastic energy density per unit-length of a dislocation. The applied elastic parameters were $\frac{E}{\mu}=2.5$ and $\nu=0.25$, with $E$, the Young's modulus, $\mu$, the shear modulus and $\nu$, the Poisson's ratio. These parameters were similar to the ones used in our study, $\frac{E}{\mu}=2.58$ and $\nu=0.29$, which were converted from the elastic constants reported in Appendix 3 by a Hill-average approximation. In their study, a dislocation density of $\sim 4 \cdot 10^{15} \mathrm{~m}^{-2}$ was reported after martensite formation, which reduced to a steady level of $\sim 3 \cdot 10^{14} \mathrm{~m}^{-2}$ after annealing at $600{ }^{\circ} \mathrm{C}$ for $600 \mathrm{~s}$. The present results are in excellent agreement with those findings.

Results from Wiessner et al. [18] were obtained by measurements with laboratory XRD and the above described evaluation method according to Christien et al. [19] on a soft martensitic stainless steel with a composition similar to the present alloy. Their results are in reasonable agreement with the ones from our study, albeit consistently a factor 3-6 lower. The dislocation density in the hardened condition was reported as $\sim 7 \cdot 10^{14} \mathrm{~m}^{-2}$ and decreased to $\sim 1 \cdot 10^{14} \mathrm{~m}^{-2}$ after iso-

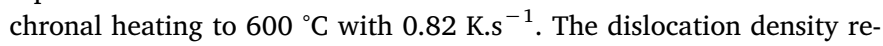
mained virtually unaffected after heating to $550{ }^{\circ} \mathrm{C}$, which is in line with the present findings.

\subsection{Coherently diffracting domain size}

In their investigation of the evolution of the dislocation density in low-carbon martensitic stainless steels, Christien et al. [19] and Wiessner et al. [18] did not report quantitative results for the size of the coherently diffracting domains as obtained from line profile broadening. Christien et al. [19] argued that for a martensite crystallite size of a few hundred nm's the contribution to line broadening is negligible compared to the contribution from strain broadening. They reported that line profile broadening was independent of the magnitude of the diffraction vector. Wiessner et al. [18] reported as well that no significant contribution from the coherently diffracting domain size could be observed.

HajyAkbary et al. [22] conducted line profile analysis on lath martensite in a Fe-0.3C-1.6Si-3.5Mn steel with laboratory XRD and determined coherently diffracting domain sizes in the range of 200-600 $\mathrm{nm}$. These domain sizes were associated with the average thickness of the martensite blocks. This interpretation of the coherently diffracting domain size would imply that lath boundaries, which are contained within the martensite blocks, would not disturb coherent Xray diffraction. Morito et al. [52] determined that on average $230 \mathrm{~nm}$ wide martensite laths in a similar Fe-0.2C-2Mn steel have an average boundary misorientation of $2.9^{\circ}$, which should conflict with coherent diffraction from martensite blocks as suggested by HajyAkbary et al. [22].

Our observations regarding the domain size are in line with the ones of Christien et al. [19] and Wiessner et al. [18]. It was found that specimens tempered up to $600{ }^{\circ} \mathrm{C}$ showed positive and negative values for the domain size with unrealistically high magnitudes of several $\mu \mathrm{m}$. The average magnitude of domain size broadening for these specimens was $0.00080 \mathrm{~nm}^{-1}$, which is significantly below the determined detector resolution of 0.0038 to $0.0081 \mathrm{~nm}^{-1}$ in the relevant range of diffraction vectors 4.5 to $13.5 \mathrm{~nm}^{-1}$ (see Appendix 2). The determined 
domain size values for these specimens are therefore not significant.

Specimens tempered in the temperature range 650 to $800{ }^{\circ} \mathrm{C}$ showed realistic domain size values of 130 to $190 \mathrm{~nm}$, which were associated with only positive domain size broadening with an average magnitude of $0.00494 \mathrm{~nm}^{-1}$. The value is larger than the detection resolution for the diffraction vectors $<7 \mathrm{~nm}^{-1}$, which includes two out of five reflections. The detector resolution is regarded an approximation rather than a strict limit and considering the reasonable and consistent values of the domain size in this temperature range, the obtained values may be significant.

Regardless of the detectability of the domain size, the merit of domain size determination with X-ray line profile analysis on martensitic steels is debatable. Martensitic steels are made up of lath-, needle- or plate-shaped, i.e. elongated, units. Since cubic symmetry of the parent phase gives rise to a range of martensitic variants ( 24 unique variants in the case of lath martensite) the well-defined shapes of martensite units cannot be directly related to a crystallographic axis. It is therefore not possible to take the crystal shape of the martensitic units into account in $\mathrm{X}$-ray line profile analysis [53]. As a consequence, the simplifying assumption of a spherical crystal (Scherrer constant of 0.9 in Eq. (2)) needs to be made. It follows that direct comparison between domain size from synchrotron X-ray diffraction with the lath size from TKD is not possible because the diffraction vector, i.e. the direction along which the domain size is determined, is generally inclined with respect to the thickness direction of the martensite laths. This implies that the domain size determined from X-ray diffraction line broadening should generally be larger than the size determined from (the current) micrographs. Then again, dislocation networks within the laths may constitute separate coherently diffracting domains. ${ }^{1}$ In this respect, Sandvik and Wayman [50] showed that the orientation of laths in an Fe-20Ni-5Mn (wt\%) alloy varied along a single lath by $<1^{\circ}$, which may be sufficient to break the coherency of the diffracted X-rays. This effect would lead to smaller values for the domain size than the size determined from micrographs. In conclusion, the value of the domain size from X-ray line profile analysis is not considered suitable to describe the unit thickness of martensite.

\subsection{Modified Williamson-Hall analysis of austenite containing specimens}

The results from X-ray line profile analysis in Fig. 7 show that the nucleation and growth of reverted austenite is not only associated with a reduction of the dislocation density, but also with an increased standard deviation of this parameter. The modified Williamson-Hall plot in Fig. 6 shows that this higher uncertainty originates from a lower goodness-of-fit value $R^{2}$ for the $650{ }^{\circ} \mathrm{C}$ condition. It was identified that the $110_{\alpha^{\prime}}, 220_{\alpha^{\prime}}$ and $200_{\alpha^{\prime}}$ reflections follow a distinct linear relationship with $K \bar{C}^{1 / 2}$, excluding the $211_{\alpha^{\prime}}$ and $321_{\alpha^{\prime}}$ reflections. While the origin of this phenomenon is unclear, some aspects of it can be discussed: It may be argued that the splitting of these reflections could originate from the elastic anisotropy of the crystal. However, all but the $200_{\alpha^{\prime}}$ reflection have the same orientation factor $H^{2}$ of 2.5 , which is in conflict with this argument. The first group of reflections, consisting of $110_{\alpha^{\prime}}, 220_{\alpha^{\prime}}$ and $200_{\alpha^{\prime}}$, only contains plane families of symmetry with relatively low multiplicity $\left(12,12\right.$ and 6 , respectively). The $220_{\alpha^{\prime}}$ reflection corresponds to the same family of crystal planes as the $110_{\alpha^{\prime}}$ reflection and thus obeys the same linear relationship in a modified Williamson-Hall plot. This corroborates the observation of two distinct

\footnotetext{
${ }^{1}$ Analogously, Ungár et al. [70] reported that the measured domain size in hierarchically, heavily deformed metallic materials, is commonly found smaller when measured with XRD line profile analysis as compared to measurements from transmission electron micrographs. While low misorientation in the range of $1-2^{\circ}$ within grains does not invoke a large contrast difference in transmission electron microscopy, scattered X-rays from such regions are not coherent and thus lead to measurement of the sub-grain size rather than the grain size [70].
}

relationships with $K \bar{C}^{1 / 2}$. The nucleation and growth of reverted austenite occurs at some of the $110_{\alpha^{\prime}}$ interfaces, while other $110_{\alpha^{\prime}}$ interfaces remain unaltered. This effect might lead to an inhomogeneous strain distribution at the $110_{\alpha^{\prime}}$ and $220_{\alpha^{\prime}}$ interfaces, which would be associated with line broadening. The second group of reflections, $211_{\alpha^{\prime}}$ and $321_{\alpha^{\prime}}$ consists of non-symmetry planes with high multiplicity (24 and 48 , respectively). It is therefore conceivable that austenite nucleation and growth has an effect on the line profiles of the first group of relatively low multiplicity, but does not alter the line profiles of the high multiplicity reflections. At higher tempering temperatures $\left(>700{ }^{\circ} \mathrm{C}\right.$ ) the splitting of the reflections faded, which is caused by the decreasing stability of austenite at these temperatures [10], leading to new martensite formation upon quenching.

\subsection{Combined discussion of results from $X$-ray line profile analysis}

Consistent with the above interpretation of the coherently diffracting domain size, the change in dislocation density as appearing from Fig. 7, can be discussed as follows. The dislocation density on tempering is first observed to decrease for temperatures exceeding $550{ }^{\circ} \mathrm{C}$ and reaches a minimum value at $650{ }^{\circ} \mathrm{C}$; while after tempering at $800^{\circ} \mathrm{C}$ (followed by quenching) it increases again. The steep decrease at $600{ }^{\circ} \mathrm{C}$ is accompanied by a realistic domain size of $130 \mathrm{~nm}$, indicating that recovery of dislocation networks within the martensite laths has occurred (see above). Speich [51] reported for low-carbon martensite, that dislocation networks recover at 500-600 ${ }^{\circ} \mathrm{C}$. Norström [54] and Grange et al. [55] both reported an effect of alloying additions on the kinetics of recovery. Addition of Mo $[54,55]$ and addition of $\mathrm{P}, \mathrm{Ni}, \mathrm{Si}, \mathrm{Cr}$ and $\mathrm{V}$ [55] were found to retard recovery, consistent with the higher recovery temperature in the present investigation. Krauss [56] reported that the kinetics of recovery is accelerated significantly by increasing the temperature, which suggests that the present tempering time of $60 \mathrm{~s}$ has led to measurable annihilation of dislocations at $600{ }^{\circ} \mathrm{C}$.

While recrystallization in Fe-C martensite occurs above $600{ }^{\circ} \mathrm{C}$ $[51,56]$, in the present alloy, relatively slow recovery competes with austenite formation at lath boundaries [10] (see Fig. 7c). Initially, tempering leads to a gradual reduction of the austenite content down to $3 \mathrm{vol} \%$ at $650{ }^{\circ} \mathrm{C}$ compared to $8 \mathrm{vol} \%$ in the hardened condition, which may be related to the decomposition of retained austenite $[57,58]$. The location and morphology of retained austenite could not be determined with microscopy methods, most likely due to surface martensite formation during sample preparation. In the case of the presence of thin films of retained austenite in between lath boundaries, these films are expected to aid elemental partitioning during tempering and the formation of reverted austenite, as no nucleation is required. Further heating leads to a second increase in austenite content up to $11 \mathrm{vol} \%$ at $750{ }^{\circ} \mathrm{C}$. This reverted austenite obtains its stability at room temperature from partitioning of $\mathrm{Ni}[10,32,59]$. Further increase of the austenite fraction at higher annealing temperature (or longer annealing time) leads to dilution of the Ni content in reverted austenite and a reduction of its stability upon cooling to room temperature. Thus, new martensite forms during quenching which explains the increase in dislocation density in martensite at $800{ }^{\circ} \mathrm{C}$.

Summarizing, $\mathrm{C}$ and $\mathrm{N}$ gradually partition to lattice defects, mainly grain boundaries, during tempering. Grain boundaries are known to act as preferred nucleation sites for reverted austenite [10,60-63] close to $\mathrm{A}_{1}$ and the locally increased interstitial content is expected to promote austenite nucleation. Recovery of martensite commences above $550{ }^{\circ} \mathrm{C}$, which is close to $A_{1}$ [64]. Both recovery and nucleation of austenite require sufficient mobility of substitutional elements. The dominating driving force for recovery is a reduction of strain energy. In the present system, solid solution of substitutional alloying elements in martensite leads to delayed recovery as compared to Fe-C martensite [54,55], while nucleation of reverted austenite at lath boundaries leads to a softening of the material $[3,65]$. Thus, in the present system, nucleation and growth of reverted austenite compete with recovery of martensite. 


\section{Conclusion}

The structural evolution of a X4CrNiMo16-5-1 soft martensitic stainless steel during tempering was investigated by analyzing synchrotron XRD line profiles, studying segregation of interstitial $\mathrm{N}$ and $\mathrm{C}$ with atom probe tomography and characterizing the morphology of martensite with orientation mapping. The main conclusions are:

- Martensite formation below $135{ }^{\circ} \mathrm{C}$ occurs without auto-tempering and leads to a dislocation density in martensite of $\sim 3.8 \cdot 10^{15} \mathrm{~m}^{-2}$.

- Tempering of martensite by heating to $475{ }^{\circ} \mathrm{C}$ with $0.033 \mathrm{~K} . \mathrm{s}^{-1}$ leads to progressive rejection of $\mathrm{C}$ and $\mathrm{N}$ from the matrix to lattice defects, mainly grain boundaries.

- Isothermal tempering for $60 \mathrm{~s}$ does not notably affect the dislocation density below $550{ }^{\circ} \mathrm{C}$.

- The dislocation density at room temperature decreases to a steady level of $\sim 3.8 \cdot 10^{14} \mathrm{~m}^{-2}$ after tempering in the temperature range 650 to $750{ }^{\circ} \mathrm{C}$.

- Austenite formation at $800{ }^{\circ} \mathrm{C}$ leads to formation of new martensite during cooling, leading to a new increase of the dislocation density.

- The average size of coherently diffracting domains was found to be below the detection limit for specimens that were tempered by heating to $600{ }^{\circ} \mathrm{C}$. The overall merit of domain size analysis for elongated features appearing in martensitic microstructures is discussed.

\section{Declaration of competing interest}

The authors declare that they have no known competing financial interests or personal relationships that could have appeared to influence the work reported in this paper.

\section{Acknowledgements}

Manuela Klaus and Christoph Genzel from Helmholtz Zentrum für Materialien und Energie (HZME) are acknowledged for their support during the activity at the HZB-BESSY II synchrotron facility and for insightful discussions during the preparation of this manuscript. Wolfgang Pantleon and Matteo Villa, Department of Mechanical Engineering at DTU, are acknowledged for discussion of the results from XRD line profile analysis. The activity was supported by the European Commission under the 7th Framework Program through the 'Research Infrastructure' action of the 'Capacities' Programme, CALIPSO (Grant n: 312284). This work was carried out owing to experimental GENESIS platform, which is supported by the Region HauteNormandie, the Metropole Rouen Normandie, the CNRS via LABEX EMC and the French National Research Agency as a part of the program "Investissements d'avenir" (ANR-11-EQPX-0020). The Danish Underground Consortium is gratefully acknowledged for financial support to the Danish Hydrocarbon Research Center (DHRTC).

\section{Data availability}

The raw and processed data required to reproduce these findings are available to download from http://dx.doi.org/10.17632/b86py6xcs8.1.

\section{Appendix 1. Instrumental broadening}

The instrumental broadening was determined by measurement of a $\mathrm{LaB}_{6}$ SRM660a NIST [66] standard powder with identical diffraction geometry and acquisition parameters as those used in all subsequent measurements. As the reference is a powder with crystallite size $>2 \mu \mathrm{m}$ and absence of micro-strains [66], its measurement does not show structural line-profile broadening and thus reveals the instrumental profile of the diffractometer. The instrumental broadening $\Delta K$ vs. the magnitude of the diffraction vector $K$ in Fig. A.1 follows the linear relationship $\Delta K=0.00312 K+0.03678$.

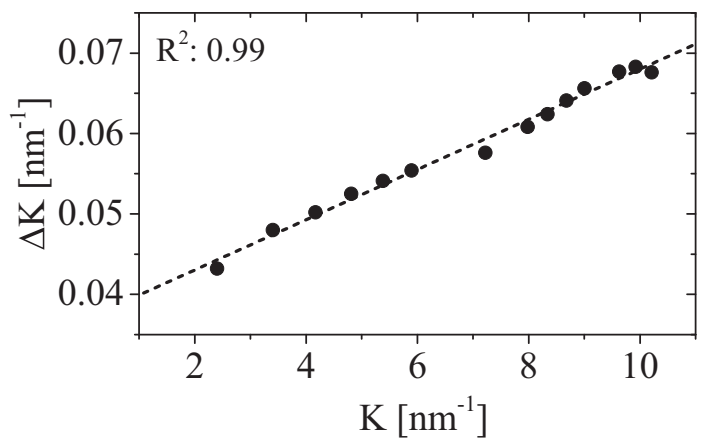

Fig. A.1. Line-profile broadening $\Delta K$ vs. magnitude of the diffraction vector $K$ of $\mathrm{LaB}_{6}$ SRM660a NIST standard powder for the determination of instrumental profile.

\section{Appendix 2. Detection limit of domain size line profile broadening}

The detection limit of domain size line profile broadening is given by the instrumental resolution, which, in energy-dispersive XRD, is dominated by the detector resolution [29,31,67]. For the present diffraction setup, data on the detector resolution as a function of energy was obtained from Ref. [45]. In this reference, the detector resolution at a dead time of $5 \%$ is given as a function of energy. The detector resolution is further measured for the $K \alpha_{2}$ line of tungsten at $59.31 \mathrm{keV}$ as a function of dead time. To approximate the resolution of the present data, the relationship of detector resolution vs. energy for a dead time of $5 \%$ was extrapolated to the present average dead time of $34 \%$. This relationship yielded detector resolutions $\Delta K_{\text {res }}$ of 0.038 and $0.081 \mathrm{~nm}^{-1}$ for the diffraction vectors with smallest and largest magnitude, 4.5 and $13.5 \mathrm{~nm}^{-1}$, respectively. Assuming that the smallest broadening that can be observed is $10 \%$ of the detector resolution [31], rearranging the y-intercept of Eq. (2) to $D_{\text {crit }}=\frac{0.9}{0.1 \Delta K_{\text {res }}}$ yields critical domain sizes of $237 \mathrm{~nm}$ and $111 \mathrm{~nm}$ for $K=4.5$ and $13.5 \mathrm{~nm}^{-1}$, respectively. Evaluating this equation with the determined instrumental broadening in Appendix 1 yields critical domain sizes of $177 \mathrm{~nm}$ and $114 \mathrm{~nm}$ for $K=4.5$ and $13.5 \mathrm{~nm}^{-1}$, respectively. The overall lower sensitivity for domain size line profile broadening described by the latter values reflects that instrumental broadening determined by measurement of a standard powder not only includes the contribution from the detector, but also from the diffraction geometry. Therefore, for the present diffraction setup domain sizes 
smaller than $\sim 110 \mathrm{~nm}$ are expected to lead to consistent and detectable line profile broadening over the entire analyzed energy range.

\section{Appendix 3. Determination of average dislocation contrast factors}

In an untextured polycrystalline aggregate, for which the population of Burgers vectors can be assumed random, the average dislocation contrast factors $\bar{C}_{h k l}$ can readily be determined when the average contrast factor $\bar{C}_{h 00}$ of the $\{h 00\}$ reflections and the parameter $q$ is known [42]:

$\bar{C}_{h k l}=\bar{C}_{h 00}\left(1-q H^{2}\right)$

where $q$ is a parameter describing the edge- or screw-character of dislocations and can be determined experimentally. $H^{2}$ is the orientation factor and can be calculated from the $h k l: H^{2}=\frac{h^{2} l^{2}+h^{2} k^{2}+l^{2} k^{2}}{\left(h^{2}+k^{2}+l^{2}\right)^{2}} . \bar{C}_{h 00}$ is determined by the dislocation contrast factors $C_{h 00}$ of pure screw and edge dislocations and the fraction of screw and edge dislocations. $C_{h 00}$ depends on the three elastic constants $c_{11}=230 \mathrm{GPa}, c_{12}=135 \mathrm{GPa}$ and $c_{44}=117 \mathrm{GPa}[68]$ of the material:

$C_{h 00, i}=a_{i}^{c}\left(1-\exp \left(-\frac{A}{b_{i}^{c}}\right)\right)+c_{i}^{c} A+d_{i}^{c}$

where A is the elastic anisotropy parameter $A=\frac{2 c_{44}}{c_{11}-c_{12}}$ [69] and the index $i$ indicates screw or edge dislocations. The parameters $a_{i}^{c}, b_{i}^{c}, c_{i}^{c}$, and $d_{i}^{c}$ depend on the ratio $c_{12} / c_{44}$ and can be found in Ref. [42]. In order to experimentally determine the parameter $q$, Eq. (A.1) is inserted into the squared form of Eq. (2) to yield the following expression [42]:

$\frac{(\Delta K-\alpha)^{2}}{K^{2}} \approx \beta \bar{C}_{h 00}\left(1-q H^{2}\right)$

where $\alpha=\left(\frac{0.9}{D}\right)^{2}$ and $\beta=\pi M^{2} b^{2} \rho / 2$. Linear regression of the left hand of Eq. (A.3) over $H^{2}$ then yields the experimental value for $q$ as the inverse $\mathrm{x}$ intercept. An example of the determination of $q$ is given in Fig. A.2.

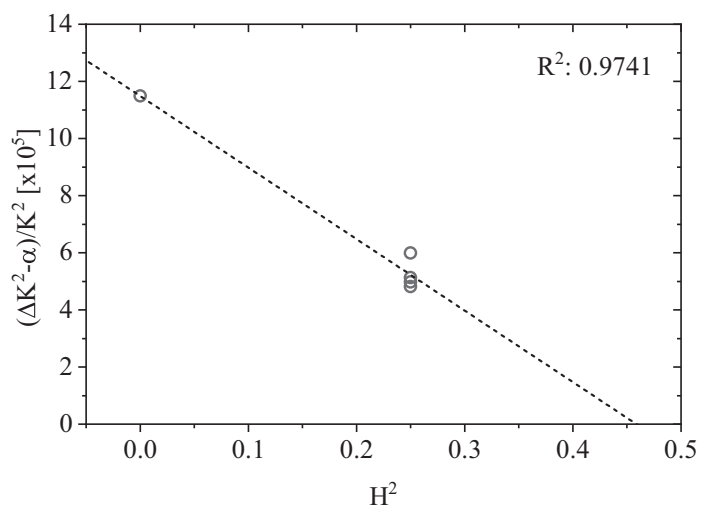

Fig. A.2. Example of experimental determination of parameter $q$ by linear regression analysis of Eq. (A.3). The parameter $q$ is obtained by the inverse x-intercept of the linear regression line.

Knowing the experimental value of $q$, the fraction of edge- and screw-dislocations can be determined by:

$f_{\text {edge }}=1-f_{\text {screw }}=\frac{q_{\text {screw }}^{\text {th }}-q}{q_{\text {screw }}^{\text {th }}-q_{\text {edge }}^{\text {th }}}$

The parameters $q_{\text {screw }}{ }^{\text {th }}$ and $q_{\text {edge }}^{\text {th }}$ are the theoretical $q$ values for full screw- and edge dislocation contribution, respectively. These factors also depend on the ratio $c_{12} / c_{44}$ of the material:

$q_{i}^{\text {th }}=a_{i}^{q}\left(1-\exp \left(-\frac{A}{b_{i}^{q}}\right)\right)+c_{i}^{q} A+d_{i}^{q}$

where $i$ indicates screw and edge dislocations and the parameters $a_{i}^{q}, b_{i}^{q}, c_{i}^{q}$, and $d_{i}^{q}$ can be found in Ref. [42]. For $A=2.46$ in this work, the parameters $q_{\text {screw }}^{\text {th }}$ and $q_{\text {edge }}{ }^{\text {th }}$ were 1.31 and 2.68 , respectively, which are typical values for $b c c$ crystals [42].

A more comprehensive description of the procedure for the determination of the average dislocation contrast factors, $\bar{C}$, can be found in Ref. [42].

\section{References}

[1] M. Grounes, S. Rao, New alloy steels for nuclear reactor pressure vessels and vessel internals, Trans. ASM 62 (1969) 902-914.

[2] H.J.J. Niederau, A new low-carbon $16 \mathrm{Cr}-5 \mathrm{Ni}$ stainless martensitic cast steel, in: G. Behal, A.S. Melilli (Eds.), Stainl. Steel Cast, ASTM, Bal Harbour, Florida, Florida, 1982, pp. 382-393.

[3] M. Al Dawood, I.S. El Mahallawi, M.E. Abd El Azim, M.R. El Koussy, Thermal aging of $16 \mathrm{Cr}-5 \mathrm{Ni}-1 \mathrm{Mo}$ stainless steel part $2-$ mechanical property characterisation, Mater. Sci. Technol. 20 (2004) 370-374, https://doi.org/10.1179/

026708304225011144.
[4] H.J. Niederau, Eigenschaften und Anwendungsmöglichkeiten der Guss- und Schmiedelegierung (G)X-5 CrNiMo 165 (Werkstoff-Nr. 1.4405), Zeitschrift Des Vereins Dtsch. Ingenieure Für Maschinenbau Und Met. Eig, 21 (1982), pp. 801-808.

[5] A.W. Marshall, J.C.M. Farrar, Welding of Ferritic and Martensitic 11-14\% Cr steels, Weld. World 45 (2001) 19-42.

[6] D.-S. Leem, Y.-D. Lee, J.-H. Jun, C.-S. Choi, Amount of retained austenite at room temperature after reverse transformation of martensite to austenite in an Fe-13\%Cr-7\%Ni-3\%Si martensitic stainless steel, Scr. Mater. 45 (2001) 767-772, https://doi.org/10.1016/S1359-6462(01)01093-4.

[7] F. Niessen, M. Villa, D. Apel, O. Keßler, M. Reich, J. Hald, M.A.J. Somers, In situ techniques for the investigation of the kinetics of austenitization of supermartensitic stainless steel, Mater. Sci. Forum 879 (2017) 1381-1386, https://doi. 
org/10.4028/www.scientific.net/MSF.879.1381.

[8] M. Kuzmina, D. Ponge, D. Raabe, Grain boundary segregation engineering and austenite reversion turn embrittlement into toughness: example of a $9 \mathrm{wt} \%$ medium Mn steel, Acta Mater. 86 (2015) 182-192, https://doi.org/10.1016/j. actamat.2014.12.021.

[9] Y. Song, D.H. Ping, F.X. Yin, X.Y. Li, Y.Y. Li, Microstructural evolution and low temperature impact toughness of a $\mathrm{Fe}-13 \% \mathrm{Cr}-4 \% \mathrm{Ni}-\mathrm{Mo}$ martensitic stainless steel, Mater. Sci. Eng. A 527 (2010) 614-618, https://doi.org/10.1016/j.msea.2009.08. 022.

[10] F. Niessen, Austenite reversion in low-carbon martensitic stainless steels - a CALPHAD-assisted review, Mater. Sci. Technol. 0836 (2018) 1-14, https://doi.org/ 10.1080/02670836.2018.1449179.

[11] W. Jiang, K. Zhao, D. Ye, J. Li, Z. Li, J. Su, Effect of heat treatment on reversed austenite in Cr15 super martensitic stainless steel, J. Iron Steel Res. Int. 20 (2013) 61-65, https://doi.org/10.1016/S1006-706X(13)60099-0.

[12] F. Niessen, M. Villa, M.A.J. Somers, Martensite formation from reverted austenite at sub-zero celsius temperature, Metall. Mater. Trans. A Phys. Metall. Mater. Sci. 49 (2018) 5241-5245, https://doi.org/10.1007/s11661-018-4887-6.

[13] S. Zhang, P. Wang, D. Li, Y. Li, Investigation of the evolution of retained austenite in Fe-13\%Cr-4\%Ni martensitic stainless steel during intercritical tempering, Mater. Des. 84 (2015) 385-394, https://doi.org/10.1016/j.matdes.2015.06.143.

[14] J.D. Escobar, G. Faria, L. Wu, J.P. Oliveira, P.R. Mei, A.J. Ramirez, Austenite reversion kinetics and stability during tempering of a Ti-stabilized supermartensitic stainless steel: correlative in situ synchrotron x-ray diffraction and dilatometry, Acta Mater. 138 (2017) 92-99, https://doi.org/10.1016/j.actamat.2017.07.036.

[15] J.D. Escobar, G. Faria, L. Wu, P.R. Mei, A.J. Ramirez, In-situ study of austenite reversion kinetics during intercritical tempering of a $12 \mathrm{Cr}-6 \mathrm{Ni}-2 \mathrm{Mo}$ Supermartensitic stainless steel, Proc. Int. Conf. Solid-Solid Phase Transform. Inorg. Mater. 2015, 2015, pp. 1127-1128, , https://doi.org/10.1081/E-EEE2-120046011.

[16] M. Villa, F. Niessen, M.A.J. Somers, In situ investigation of the evolution of lattice strain and stresses in austenite and martensite during quenching and tempering of steel, Metall. Mater. Trans. A. 49 (2018) 28-40, https://doi.org/10.1007/s11661 017-4387-0.

[17] T. Maki, Morphology and substructure of martensite in steels, in: F. Perelome, D.V. Edmonds (Eds.), Phase Transform. Steels Vol. 2 Diffus. Transform. High Strength Steels, Model. Adv. Anal. Tech, 1st ed., Woodhead Publishing, 2012, pp. $34-58$.

[18] M. Wiessner, E. Gamsjäger, S. van der Zwaag, P. Angerer, Effect of reverted austenite on tensile and impact strength in a martensitic stainless steel - an in-situ Xray diffraction study, Mater. Sci. Eng. A 682 (2017) 117-125, https://doi.org/10. 1016/j.msea.2016.11.039.

[19] F. Christien, M.T.F. Telling, K.S. Knight, Neutron diffraction in situ monitoring of the dislocation density during martensitic transformation in a stainless steel, Scr. Mater. 68 (2013) 506-509, https://doi.org/10.1016/j.scriptamat.2012.11.031.

[20] F. Niessen, M. Villa, F. Danoix, J. Hald, M.A.J. Somers, In-situ analysis of redistribution of carbon and nitrogen during tempering of low interstitial martensitic stainless steel, Scr. Mater. 154 (2018) 216-219, https://doi.org/10.1016/j. scriptamat.2018.06.004.

[21] M.K. Miller, G.D.W. Smith, Atom Probe Microanalysis: Principles and Applications to Materials Problems, Materials Research Society, USA, 1989.

[22] F. HajyAkbary, J. Sietsma, A.J. Böttger, M.J. Santofimia, An improved X-ray diffraction analysis method to characterize dislocation density in lath martensitic structures, Mater. Sci. Eng. A 639 (2015) 208-218, https://doi.org/10.1016/j. msea.2015.05.003.

[23] F. Niessen, A. Burrows, A.B.D.S. Fanta, A systematic comparison of on-axis and offaxis transmission Kikuchi diffraction, Ultramicroscopy 186 (2018) 158-170, https://doi.org/10.1016/j.ultramic.2017.12.017.

[24] J.J. Fundenberger, E. Bouzy, D. Goran, J. Guyon, H. Yuan, A. Morawiec, Orientation mapping by transmission-SEM with an on-axis detector, Ultramicroscopy 161 (2016) 17-22, https://doi.org/10.1016/j.ultramic.2015.11.002.

[25] W. Sha, L. Chang, G.D.W. Smith, L. Cheng, E.J. Mittemeijer, Some aspects of atomprobe analysis of Fe-C and Fe-N systems, Surf. Sci. 266 (1992) 416-423.

[26] F. Danoix, G. Grancher, A. Bostel, D. Blavette, Standard deviations of composition measurements in atom probe analyses-part II: 3D atom probe, Ultramicroscopy 107 (2007) 739-743, https://doi.org/10.1016/j.ultramic.2007.02.005.

[27] C. Genzel, I. Denks, M. Klaus, The materials science beamline EDDI for energydispersive analysis of subsurface residual stress gradients, Mater. Sci. Forum 524-525 (2006) 193-198, https://doi.org/10.4028/www.scientific.net/MSF.524525.193.

[28] H.-Z.B. für M. und Energie, The 7T-MPW-EDDI beamline at BESSY II, J. Large-Scale Res. Facil. 2 (2016) 1-6.

[29] D. Apel, M. Klaus, C. Genzel, D. Balzar, Rietveld refinement of energy-dispersive synchrotron measurements, Zeitschrift Fur Krist. 226 (2011) 934-943, https://doi. org/10.1524/zkri.2011.1436.

[30] J.W. Otto, On the peak profiles in energy dispersive powder X-ray diffraction with synchrotron radiation, J. Appl. Crystallogr. 30 (1997) 1008-1015, https://doi.org/ 10.1107/S0021889897005451.

[31] L. Gerward, S. Mørup, H. Topsøe, Particle size and strain broadening in energydispersive x-ray powder patterns, J. Appl. Phys. 47 (1976) 822-825, https://doi. org/10.1063/1.322714.

[32] F. Niessen, F.B. Grumsen, J. Hald, M.A.J. Somers, Formation and stabilization of reversed austenite in supermartensitic stainless steel, Proc. 24th IFHTSE Congr, 2017, pp. 138-145.

[33] S. Morito, X. Huang, T. Furuhara, T. Maki, N. Hansen, The morphology and crystallography of lath martensite in alloy steels, Acta Mater. 54 (2006) 5323-5331, https://doi.org/10.1016/j.actamat.2006.07.009.
[34] M. Thuvander, J.J. Weidow, J. Angseryd, L.K.L. Falk, F. Liu, M. Sonestedt, K. Stiller, H.O. Andrén, Quantitative atom probe analysis of carbides, Ultramicroscopy 111 (2011) 604-608, https://doi.org/10.1016/j.ultramic.2010.12.024.

[35] G. Miyamoto, K. Shinbo, T. Furuhara, Quantitative measurement of carbon content in Fe-C binary alloys by atom probe tomography, Scr. Mater. 67 (2012) 999-1002, https://doi.org/10.1016/j.scriptamat.2012.09.007.

[36] U. Rolander, H.-O. Andren, Statistical correction for pile-up in the atom-probe detector system, Colloq. Phys. 50 (1989) 529-534.

[37] B.M. Jenkins, F. Danoix, M. Gouné, P.A.J. Bagot, Z. Peng, M.P. Moody, B. Gault, Reflections on the analysis of interfaces and grain boundaries by atom probe tomography, Microsc. Microanal. 26 (2020) 247-257, https://doi.org/10.1017/ S1431927620000197.

[38] L. Cheng, A. Böttger, T.H. de Keijser, E.J. Mittemeijer, Lattice parameters of ironcarbon and iron-nitrogen martensites and austenites, Scr. Metall. Mater. 24 (1990) 509-514, https://doi.org/10.1016/0956-716X(90)90192-J.

[39] P. Thompson, D.E. Cox, J.B. Hastings, Rietveld refinement of Debye-Scherrer synchrotron X-ray data from $\mathrm{Al}_{2} \mathrm{O}_{3}$, J. Appl. Crystallogr. 20 (1987) 79-83.

[40] T.H. de Keijser, J.I. Langford, E.J. Mittemeijer, A.B.P. Vogels, Use of the Voigt function in a single-line method for the analysis of X-ray diffraction line broadening, J. Appl. Crystallogr. 15 (1982) 308-314, https://doi.org/10.1107/ S0021889882012035.

[41] J.J. Olivero, R.L. Longbothum, Empirical fits to the Voigt line width: a brief review, J. Quant. Spectrosc. Radiat. Transf. 17 (1977) 233-236.

[42] T. Ungár, I. Dragomir, Á. Révész, A. Borbély, The contrast factors of dislocations in cubic crystals: the dislocation model of strain anisotropy in practice, J. Appl. Crystallogr. 32 (1999) 992-1002, https://doi.org/10.1107/S0021889899009334.

[43] M. Wilkens, K. Herz, H. Mughrabi, An x-ray diffraction study of cyclically and of unidirectionally deformed copper single crystals, Zeitschrift Für Met. 71 (1980) 376-384 (papers2://publication/uuid/0BDACD3E-1E56-4F13-BB21 C86877A30B2F).

[44] T. Ungár, A. Borbély, The effect of dislocation contrast on x-ray line broadening: a new approach to line profile analysis, Appl. Phys. Lett. 69 (1996) 3173-3175, https://doi.org/10.1063/1.117951.

[45] I.A. Denks, C. Genzel, Enhancement of energy dispersive residual stress analysis by consideration of detector electronic effects, Nucl. Instruments Methods Phys. Res. Sect. B Beam Interact. with Mater. Atoms. 262 (2007) 87-94, https://doi.org/10. 1016/j.nimb.2007.05.007.

[46] R.W. Hinton, Interlaboratory evaluation of ASTM practice for X-ray determination of retained austenite in steel with near-random crystallographic orientation (E 975), J. Test. Eval. 15 (1987) 95-100.

[47] S. Allain, F. Danoix, M. Goune, K. Hoummada, D. Mangelinck, Static and dynamica ageing processes at room temperature in a $\mathrm{Fe} 25 \mathrm{NiO}$. 4C virgin martensite: effect of C redistribution at the nanoscale, Philos. Mag. Lett. 93 (2013) 68-76, https://doi. org/10.1080/09500839.2012.742590.

[48] L. Karlsson, H.O. Andrén, H. Nordén, Grain boundary segregation in an austenitic stainless steel containing boron - an atom-probe study, Scr. Metall. 16 (1982) 297-302.

[49] L. Karlsson, H. Nordén, Overview no. 63 non-equilibrium grain boundary segregation of boron in austenitic stainless steel-IV. Precipitation behaviour and distribution of elements at grain boundaries, Acta Metall. 36 (1988) 35-48, https:// doi.org/10.1016/0001-6160(88)90026-0.

[50] B.P.J. Sandvik, C.M. Wayman, Characteristics of lath martensite: part I Crystallographic and substructural features, Metall. Trans. A 14 (1983) 809-822, https://doi.org/10.1007/BF02644284.

[51] G.R. Speich, Tempering of low-carbon martensite, Trans. Metall. Soc. AIME 245 (1969) 2553-2564.

[52] S. Morito, H. Yoshida, T. Maki, X. Huang, Effect of block size on the strength of lath martensite in low carbon steels, Mater. Sci. Eng. A 438-440 (2006) 237-240, https://doi.org/10.1016/j.msea.2005.12.048.

[53] J.I. Langford, A.J.C. Wilson, Scherrer after sixty years: a survey and some new results in the determination of crystallite size, J. Appl. Crystallogr. 11 (1978) $102-113$.

[54] L.Å. Norström, The relation between microstructure and yield strength in tempered low-carbon lath martensite with 5\% nickel, Met. Sci. (1976) 429-436.

[55] R.A. Grange, C.R. Hribal, L.F. Porter, Hardness of tempered martensite in carbo and low-alloy steels, Metall. Trans. A. 8 (1977) 1775-1785, https://doi.org/10. 1007/BF02646882.

[56] G. Krauss, Tempering of lath martensite in low and medium carbon steels: assessment and challenges, Steel Res. Int. 87 (2017) 1700038, , https://doi.org/10.1002/ srin. 201700038.

[57] A. Bojack, L. Zhao, P.F. Morris, J. Sietsma, In situ thermo-magnetic investigation of the austenitic phase during tempering of a 13Cr6Ni2Mo supermartensitic stainles steel, Metall. Mater. Trans. A Phys. Metall. Mater. Sci. 45 (2014) 5956-5967, https://doi.org/10.1007/s11661-014-2551-3.

[58] M. De Sanctis, G. Lovicu, R. Valentini, A. Dimatteo, R. Ishak, U. Migliaccio, R. Montanari, E. Pietrangeli, Microstructural features affecting tempering behavior of $16 \mathrm{Cr}-5 \mathrm{Ni}$ supermartensitic steel, Metall. Mater. Trans. A Phys. Metall. Mater. Sci. 46 (2015) 1878-1887, https://doi.org/10.1007/s11661-015-2811-x.

[59] J.D. Escobar, J.D. Poplawsky, G.A. Faria, J. Rodriguez, J.P. Oliveira, C.A.F. Salvador, P.R. Mei, S.S. Babu, A.J. Ramirez, Compositional analysis on the reverted austenite and tempered martensite in a Ti-stabilized supermartensitic stainless steel: segregation, partitioning and carbide precipitation, Mater. Des. 140 (2015) 95-105, https://doi.org/10.1016/j.matdes.2017.11.055.

[60] R. Schnitzer, R. Radis, M. Nöhrer, M. Schober, R. Hochfellner, S. Zinner, E. Povoden-Karadeniz, E. Kozeschnik, H. Leitner, Reverted austenite in PH 13-8 Mo maraging steels, Mater. Chem. Phys. 122 (2010) 138-145, https://doi.org/10. 
1016/j.matchemphys.2010.02.058.

[61] Y.-K. Lee, H.-C. Shin, D.-S. Leem, J.-Y. Choi, W. Jin, C.-S. Choi, Reverse transformation mechanism of martensite to austenite and amount of retained austenite after reverse transformation in $\mathrm{Fe}-3 \mathrm{Si}-13 \mathrm{Cr}-7 \mathrm{Ni}$ (wt-\%) martensitic stainless steel, Mater. Sci. Technol. 19 (2003) 393-398, https://doi.org/10.1179/026708303225009742.

[62] W.H. Yuan, X.H. Gong, Y.Q. Sun, J.X. Liang, Microstructure evolution and precipitation behavior of $0 \mathrm{Cr} 16 \mathrm{Ni5M}$ martensitic stainless steel during tempering process, J. Iron Steel Res. Int. 23 (2016) 401-408, https://doi.org/10.1016/S1006706X(16)30063-2.

[63] Y.Y. Song, X.Y. Li, L.J. Rong, Y.Y. Li, T. Nagai, Reversed austenite in 0Cr13Ni4Mo martensitic stainless steels, Mater. Chem. Phys. 143 (2014) 728-734, https://doi. org/10.1016/j.matchemphys.2013.10.006

[64] F. Niessen, M. Villa, J. Hald, M.A.J. Somers, Kinetics Analysis of Two-stage Austenitization in Supermartensitic Stainless Steel, vol. 116, (2017), pp. 8-15, https://doi.org/10.1016/j.matdes.2016.11.076.

[65] M. Al Dawood, I.S. El Mahallawi, M.E. Abd El Azim, M.R. El Koussy, Thermal aging of $16 \mathrm{Cr}-5 \mathrm{Ni}-1 \mathrm{Mo}$ stainless steel part 1 - microstructural analysis, Mater. Sci. Technol. 20 (2004) 363-369, https://doi.org/10.1179/026708304225011135.

[66] National Institute of Standards \& Technology, Certificate - Standard Reference Material 660a, Lanthanum Hexaboride Powder - Line Position and Line Shape Standard for Powder Diffraction, http://scholar.google.com/scholar?hl=en\& btnG $=$ Search\&q = intitle:Standard + Reference + Material + +660a\#4, (2000).

[67] J.W. Otto, On the peak profiles in energy-dispersive powder x-ray diffraction with synchrotron radiation, J. Appl. Crystallogr. 30 (1997) 1008-1015, https://doi.org/ 10.1107/S0021889897005451.

[68] S.A. Kim, W.L. Johnson, Elastic constants and internal friction of martensitic steel, ferritic-pearlitic steel, and alpha-iron, Mater. Sci. Eng. A 452-453 (2007) 633-639, https://doi.org/10.1016/j.msea.2006.11.147.

[69] C. Zener, Elasticity and Anelasticity of Metals, University of Chicago Press, 1948.

[70] T. Ungár, G. Tichy, J. Gubicza, R.J. Hellmig, Correlation between subgrains and coherently scattering domains, Powder Diffract. 20 (1948) 366-375, https://doi. org/10.1154/1.2135313. 